\title{
Einstein e Picasso: mera coincidência?
}

\author{
Einstein and Picasso: mere coincidence?
}

Entrevista com

Arthur I. Miller

Professor Emérito de história e filosofia da ciência

Departamento de Estudos em Ciência e Tecnologia

University College - London Gower Street

WC1E 6BT London, UK

sts@ucl.ac.uk

Entrevista concedida a

Luisa Massarani,

Carla Almeida

(em 19.7.2005)

Centro de Estudos do

Museu da Vida

Casa de Oswaldo Cruz/Fiocruz Av. Brasil 4.365, Manguinhos 21045-900 Rio de Janeiro - RJ Brasil

lumassa@fiocruz.br e

carlalmeida@coc.fiocruz.br

\section{José Claudio Reis}

Professor do Colégio Pedro II e da Escola Dinâmica de Ensino Moderno (EDEM) no Rio de Janeiro, integrante do Grupo Teknê

grupo@tekne.pro.br

www.tekne.pro.br/home.htm
MILLER, A. I. Einstein e Picasso: mera coincidência?. (Entrevista concedida a Luisa Massarani, Carla Almeida e José Claudio Reis).

História, Ciências, Saúde-Manguinhos, v. 13 (suplemento), p. 223-31, outubro 2006.

Professor de história e filosofia da ciência em Londres, no Reino Unido, Arthur I. Miller fala nesta entrevista sobre os paralelos existentes entre as vidas e as obras de Albert Einstein e Pablo Picasso, tema do livro Einstein \& Picasso: Space, time, and the beauty that causes havoc, de sua autoria. Ele conta como se interessou pelo tema e relata as principais descobertas que fez ao longo da pesquisa para o livro. O fato de ambos terem produzido seus trabalhos mais importantes no mesmo períodoEinstein formulou a Teoria da Relatividade Especial em 1905 e Picasso pintou Les Demoiselles D'Avignon em 1907 - motivou Miller a estudar mais profundamente a relação entre eles. E sua principal descoberta foi a de que essa produção quase simultânea vai bastante além de uma mera coincidência.

PALAVRAS-CHAVE: Einstein; Picasso; ciência; arte.

MILLER, A. I. Einstein and Picasso: mere coincidence? (Interviewed by Luisa Massarani, Carla Almeida, and José Claudio Reis).

História, Ciências, Saúde-Manguinhos, v. 13 (supplement), p. 223-31, October 2006.

In this interview, Arthur I. Miller, professor of history and philosophy of science in London, discusses the parallels between the lives and works of Albert Einstein and Pablo Picasso, topic of his book Einstein \& Picasso: Space, time, and the beauty that causes havoc. He tells what drew him to the topic and talks about the major discoveries he made while researching the book. The fact that both men did their most valuable work during the same period - Einstein devised his theory of special relativity in 1905, while Picasso painted Les Demoiselles D'Avignon in 1907 - prompted Miller to take a deeper look at the relation between them. His main finding was that their nearly simultaneous production went well beyond a mere coincidence.

KEYWORDS: Einstein; Picasso; science; art. 


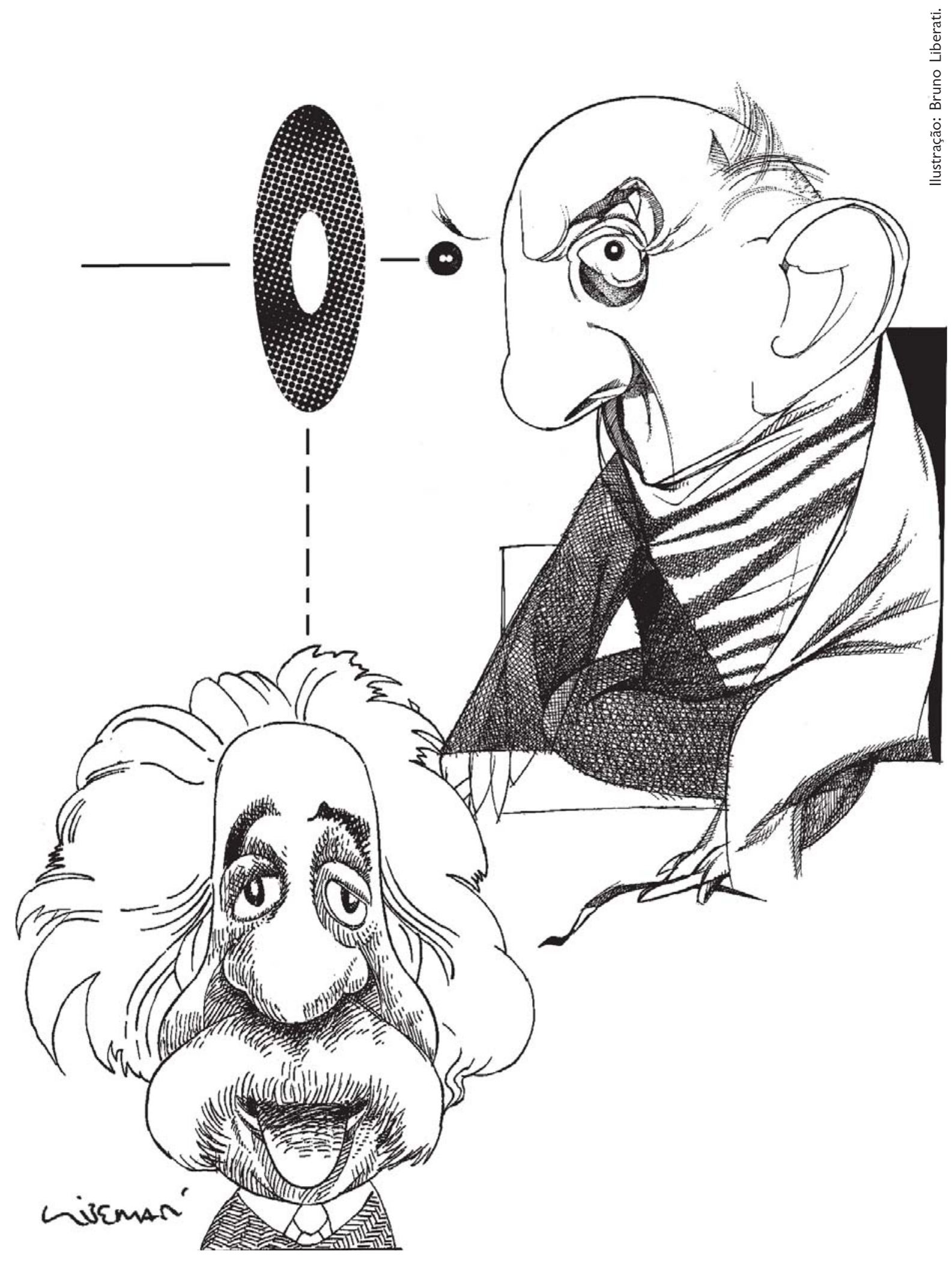


A relação entre a ciência e a arte tem uma trajetória instável ao longo da história. A obra de Leonardo da Vinci, de um lado, pode ser considerada um dos momentos onde essa interação esteve forte. A instituição da ciência moderna, de outro, parece ter conduzido a um distanciamento crescente entre as duas manifestações.

No início do século $X X$, todavia, tanto a ciência como a arte vivem momentos de grande ruptura. Enquanto na Suíça Albert Einstein formula, em 1905, a Teoria da Relatividade, revolucionando o mundo da física, Pablo Picasso pinta em Paris, em 1907, Les Demoiselles d'Avignon, causando uma ruptura no campo da arte.

Intrigado pelo fato de o maior cientista do século XX e o artista mais famoso do mesmo período terem produzido seus trabalhos de maior impacto quase ao mesmo tempo, o físico norte-americano Arthur Miller, professor de história e filosofia da ciência do University College London (Reino Unido), decidiu estudar a fundo vida e obra de Einstein e Picasso e o contexto histórico da época em que tiveram seus picos de criatividade.

O resultado dessa pesquisa, que remete à década de 1970, está no livro Einstein \& Picasso: space, time, and the beauty that causes havoc. Miller veio ao Brasil em julho de 2005 falar sobre esse trabalho. Em Fortaleza, uma das três cidades em que proferiu palestra, o físico concedeu a seguinte entrevista a Carla Almeida, Luisa Massarani e José Claudio Reis, na qual mostra que os paralelos existentes entre Einstein e Picasso não são apenas coincidência. Segundo Miller, ambos respondiam, cada um à sua maneira, às idéias revolucionárias da avant garde, movimento intelectual que abrangia toda a Europa no início do século XX e questionava as visões clássicas sobre espaço e tempo - o ponto principal dos trabalhos de Einstein e Picasso.

\section{Como você veio a se interessar pela interface entre ciência e arte?}

Durante toda a minha formação em física, eu estava interessado de fato em entender a natureza das perguntas. Decidi, assim, alguns anos depois de receber o título de PhD em física, aprofundarme na história e filosofia da física. Lendo os artigos científicos originais em alemão sobre a Teoria da Relatividade e a Teoria Quântica, fiquei perplexo com a importância da imagem visual, com o modo pelo qual ela é formada em nossa mente, como é usada e armazenada. E, claro, quando estudamos imagem visual, somos levados naturalmente à relação entre ciência e arte e às noções de estética e beleza; o que são elas de fato?

Por que Einstein e Picasso, especificamente?

Quanto a Einstein e Picasso, sempre me deixou intrigado o fato de terem feito seus trabalhos mais importantes quase ao mesmo 
tempo: Einstein formulou a Teoria da Relatividade Especial em 1905 e Picasso produziu Les Demoiselles D'Avignon em 1907. Ambos os trabalhos tratavam do mesmo problema: a natureza do espaço e tempo e, particularmente, a natureza da simultaneidade. Isto seria obra do acaso? Pesquisando sobre o assunto descobri que não; ambos respondiam à avant garde, as ondas intelectuais que inundavam a Europa. O principal interesse da avant garde era a natureza do espaço e do tempo, era o questionamento das maneiras intuitivas clássicas de se entender isso. Esse questionamento foi se difundindo por diversas áreas como arquitetura, arte, música e, é claro, física. Picasso e Einstein estavam respondendo, cada um à sua maneira, a esse movimento.

Quais são os principais paralelos encontrados nas vidas pessoais e profissionais de Einstein e Picasso?

O principal paralelo, em se tratando de ciência, é que ambos estavam interessados na mesma questão, a natureza do espaço e do tempo e, particularmente, na natureza da simultaneidade. Em suas vidas pessoais, eles tinham problemas bastante similares; tinham, por exemplo, problemas com mulheres. Na época em que produziam seus trabalhos mais importantes, passavam por uma fase turbulenta em seus relacionamentos amorosos. Eles sugavam energia dessas pessoas, e acho que sugavam energia de todos aqueles que estavam às suas voltas, concentrando essa energia nas questões em que trabalhavam. Outro paralelo é que nem Einstein nem Picasso abandonaram seus fundamentos clássicos. Einstein continuou sendo um físico clássico e Picasso optou por figuras e formas clássicas, embora não no sentido pré-cubista. Einstein nunca aceitou a mais incrível previsão da Relatividade Geral - os buracos negros. Picasso nunca participou do expressionismo abstrato. Na verdade, em uma fase mais avançada do cubismo, em 1910-1911, ele conscientemente se distanciou da super-geometrização. Ele colava, por exemplo, pedaços de corda e papel de parede nas telas com o objetivo de mostrar que o observador continuava preso ao mundo em que vivemos.

No seu livro Einstein, Picasso: space, time, and the beauty that causes havoc, você menciona também que Einstein e Picasso tinham seus grupos de discussão, onde trocavam idéias sobre quase tudo...

O que me deixou perplexo em relação a Einstein e Picasso é que eles foram as primeiras pessoas a usar grupos interdisciplinares de discussão. Eles tinham amigos e colegas que organizavam círculos literários e os alimentavam com informações, as quais seriam reinterpretadas por eles de diversas maneiras criativas. Ambos tinham seus grupos de discussão. Einstein tinha a "Academia Olimpia" e Picasso tinha la bande à Picasso. Em relação aos lugares 
em que produziram seus trabalhos mais criativos, é interessante que Einstein tenha deixado o escritório de patentes em 1909 e Picasso tenha deixado Le Bateau-Lavoir em 1909. Além disso, seus trabalhos de ruptura não foram imediatamente reconhecidos pelo que eram. Eles eram apreciados, se eram, por razões completamente equivocadas. Prova disso é Einstein ainda ter ficado quatro anos no escritório de patentes. Sua Teoria da Relatividade foi interpretada inicialmente como um embelezamento da teoria do elétron, que era de outra pessoa. Les Demoiselles D'Avignon, de Picasso, não foi exibida publicamente até 1916 e só foi vendida em 1926.

Einstein e Picasso debatiam os mesmos assuntos em seus grupos de discussão?

$\mathrm{Na}$ "Academia Olimpia" debatiam-se todos os campos do conhecimento. Seus integrantes discutiam desde a filosofia grega até a filosofia do começo do século XX; falavam sobre literatura, ciência e tecnologia. O núcleo do grupo eram Einstein, Conrad Habicht e Maurice Solovine. Outras pessoas, no entanto, eram convidadas a participar das sessões. Mileva, a esposa de Einstein, participava de tempos em tempos, mas nunca contribuiu muito. Desnecessário dizer que eles discutiam o que estava acontecendo no campo da física. Na "Academia Olimpia", Einstein expôs suas idéias sobre uma teoria da relatividade-de espaço e tempo. Sabe-se que ele teve também conversas particularmente importantes com uma pessoa com quem manteve amizade durante toda a vida - Michele Besso, imortalizado por uma nota de agradecimento no artigo de Einstein sobre a relatividade, de 1905 . O núcleo de la bande à Picasso não era composto por artistas, mas por escritores da nova geração - André Salmon, Guillaume Apollinaire e Max Jacob. Eles mantinham Picasso informado sobre novas descobertas nos campos da arte, literatura e ciência. Mas, no que se refere à ciência, a pessoa que mais ajudou Picasso foi Maurice Princet. Ele era um membro marginal do grupo. Estatístico preciso, Princet também era matemático amador - interessado em tópicos avançados da geometria e em sua filosofia. Ele introduziu Picasso nesse tópico e também o apresentou aos escritos do polímata francês Henri Poincaré. Quando descobri essa conexão, tive uma grande surpresa - os escritos de Poincaré também tiveram grande importância para as idéias de Einstein que o levaram à descoberta da Teoria da Relatividade, em 1905.

Qual a influência de Poincaré em cada um?

Os escritos de Poincaré sobre espaço e tempo interessavam a ambos. A Einstein, interessavam suas idéias sobre como sincronizar relógios e sobre a importância da relatividade. A Picasso, interessava seu trabalho sobre como geômetras podem visualizar a quarta dimensão. 
Poincaré chegou perto da teoria da relatividade. Ele tinha em mãos as mesmas informações que Einstein, mas foi Einstein que chegou lá. Como você avalia o ocorrido?

O interessante nesse episódio é que tanto Einstein quanto Poincaré tinham a mesma informação experimental à disposição e eles representaram aquela informação experimental com as mesmas fórmulas matemáticas, mas Einstein interpretou aquela informação como uma teoria da relatividade e Poincaré como uma teoria do elétron. O que fez a diferença para Einstein foram suas considerações sobre simetria e o uso que fez de experimentos conceituais; foi isso que Poincaré não levou em consideração. Desta maneira, Einstein conseguiu dar um passo em direção à concepção acima da percepção. Poincaré não descobriu a relatividade, mesmo tendo toda a formulação matemática; ele não deu esse salto porque não levou em consideração a natureza do tempo, a natureza da simultaneidade. Einstein levou. Percepção acima da concepção era a maneira pela qual ciência e arte eram feitas até então. Einstein e Picasso viraram a mesa. Eles reverteram isto. Essa reversão se deu através do aumento da abstração. Maior abstração levou-os à descoberta de uma nova estética. Para Einstein, a estética era minimalista, e para Picasso a nova estética era a redução de formas geométricas.

A quarta dimensão chegou à literatura antes dos trabalhos de Poincaré. $O$ livro The time machine, de H. G. Wells, foi publicado em 1895. A literatura teve alguma influência nos trabalhos de Einstein e Picasso?

H. G. Wells foi a primeira pessoa a escrever sobre a quarta dimensão. Não encontrei provas da influência dele em Einstein. Eu não tenho certeza se, naquela época, H. G. Wells era lido em outra língua além do inglês. E certamente ele não teve nenhuma influência em Picasso. No entanto, a concepção de tempo como a quarta dimensão não foi discutida até 1907, dois anos após a Teoria da Relatividade. Foi de 1907 em diante que o tempo apareceu na literatura como a quarta dimensão. Embora Poincaré já tivesse escrito isso, a idéia não foi introduzida na física de forma que os físicos se tornassem interessados no assunto. Porque eles estavam se concentrando nas idéias da teoria de Einstein, e o que Poincaré estava fazendo era muito matemático. De qualquer maneira, nunca soube de nenhuma menção a H. G. Wells feita por Minkowski ou Max Born, outro físico famoso. E eles liam amplamente, até mesmo em inglês. Até onde sei, não leram H. G. Wells.

\section{Quando começou a pesquisa para o livro?}

No que se refere a Einstein e Poincaré, há uma longa trajetória que nos leva de volta ao início dos anos 70. Em 1976, tive a grande sorte de descobrir em Paris todos os artigos e manuscritos de 
Poincaré. Estavam na casa de seu neto. Em relação a Picasso, fui achando material ao longo dos anos, mas passei o ano de 1999 fazendo um intenso trabalho de pesquisa no Museu Picasso, em Paris, onde tudo relacionado a Picasso está em um único espaço, não muito grande. Espantoso!

No seu livro, você cita a seguinte frase de Picasso: "Pinturas são nada mais que pesquisa experimento. Nunca pinto um quadro como um trabalho de arte. Todos são pesquisa. Pesquiso constantemente e há uma seqüência lógica em toda esta pesquisa". Como você mesmo diz, Picasso gostava de brincar com repórteres, sendo algumas vezes bastante irônico e exagerado... Você acredita que ele realmente queria dizer isto?

Acho que ele queria dizer isso mesmo. No meu livro, discuto que era preciso ser muito cuidadoso com o que Picasso dizia em entrevistas, porque ele gostava de brincar com jornalistas. Mas acho que ele estava sendo sincero quando disse isso, principalmente no caso de Les Demoiselles d'Avignon. Há milhares de esboços feitos por ele. Ele trabalhou bastante nesse sentido durante os anos cubistas. Os anos foram então passando até ele fazer Guernica, em 1937, e ali ele voltou a esse estilo de trabalhar, o mesmo do Les Demoiselles d'Avignon, numerando e datando os esboços. Essa é uma ótima citação.

Qual foi o impacto dos trabalhos de Einstein sobre simetria no campo das artes?

Einstein introduziu a noção de simetria na física no século XX, com os três artigos que escreveu em 1905. Foi o trabalho de Picasso na redução das formas através da geometria que teve impacto nas artes. Na verdade, a parte da Teoria da Relatividade que os artistas achavam extremamente interessante era $E=m c^{2}$. A massa, de um lado, algo substancial, como uma mesa e uma cadeira; a energia, de outro, amórfica, espalhada, em todo lugar. $\mathrm{E}=\mathrm{mc}^{2}$ iguala estas duas entidades (através da velocidade da luz). Os artistas entenderam isso de uma forma excitante e imaginativa, o que levou ao "expressionismo abstrato". Foi isto que influenciou Kandinsky, cujo quadro de 1910, Improvisation, foi o primeiro quadro abstrato expressionista.

Os estudos sobre ciência e arte se concentram geralmente em momentos de crise na história. Como essa relação flui quando esse não é o caso?

A história da ciência e da arte remete aos tempos de Leonardo da Vinci e Galileu Galilei, que eram artistas e cientistas. Com o início da ciência moderna, houve uma ruptura entre elas. A arte passou a ser considerada frívola, e a ciência, uma coisa real. Penso que agora elas estão se unindo novamente, pois vivemos em uma cultura extremamente visual, trabalhamos em frente ao computador... Acredito que, daqui a alguns milhares de anos, haverá uma 
nova linguagem para se fazer ciência, uma linguagem arte/ciência pela qual será possível de fato desenhar de forma criativa em uma tela de cristal líquido.

Você acredita que as novas tecnologias aplicadas à arte - novas tintas, novos processos... - irão aproximar os artistas da ciência e da tecnologia?

Certamente. Novas tecnologias em arte sempre cresceram junto com a ciência. Em meados do século XIX, a fotografia foi inventada e outras tecnologias emergiram, como a produção de tintas em tubos, que possibilitaram aos artistas usufruir de grande liberdade. É interessante mencionar aqui um episódio em que a arte influenciou a tecnologia - a invenção da fotografia colorida, por Gabriel Lippmann, resultou da observação das pinturas de Georges Seurat. Tem havido numerosas interações entre ciência e arte no século $\mathrm{XX}$, mas, nos dias de hoje, em que vivemos em uma cultura altamente visual, elas estão se aproximando ainda mais.

\section{E Salvador Dalí? Como você analisa a relação do pintor com a ciência?}

Não li muito sobre ele, mas as pessoas sempre citam a relação de Dalí com a física. Claramente ele sabia da relatividade do tempo em suas pinturas de relógios. Dalí lia um pouco sobre ciência, assim como Marcel Duchamp, e eles de fato usaram um pouco de física em seus quadros.

Há uma tendência atual, na divulgação científica, de se usar a arte como ferramenta de popularização da ciência. Como você avalia isso?

Considero uma boa idéia usar novas maneiras de se falar de ciência, que não as usuais. A peça Copenhagen é um ótimo exemplo. Michael Frayn tem um pouco de formação científica. Ele diz que tirou a idéia para a peça de um livro de Thomas Powers sobre Heisenberg. Em uma parte do livro, Powers conta que em setembro de 1941 Heisenberg e Bohr se encontraram em Copenhagen e nunca ninguém soube ao certo sobre o que falaram, mas aquele encontro os deixou muito perturbados e os marcou para o resto da vida. Frayn disse: "Bem, isso é alimento para dramaturgos". O interessante é que mesmo as pessoas que nada sabiam sobre física atômica sentaram-se lá e aproveitaram. Perguntei a ele como conseguia fazer isso. Todas as peças que havia escrito até então tinham temas mais leves... Ele fez um trabalho genial. Desenho animado também é um bom exemplo. Às vezes, é a única maneira de passar a mensagem, porque não há como fotografar alguém apontando para um buraco negro, por exemplo.

Falando em buraco negro, conte-nos sobre seu novo livro.

É uma história de aventura que aborda o postulado sobre buracos negros, apresentado na década de 1930 por um físico indiano 
chamado Subrahmanyan Chandrasekhar, Chandra, e a maneira como Eddington, um dos maiores astrofísico da época, rejeitou-o. Quatro anos antes de Chandra, Eddington havia sugerido a existência dos buracos negros. Mas quando apareceu um garoto indiano de 19 anos mostrando que isso podia de fato ser verdade, Eddington o atacou visceralmente, tão visceralmente que acabou arruinando as vidas de ambos. Cabe lembrar que todo mundo achava o conceito de buraco negro um tanto ridículo, mesmo que seguisse logicamente a Teoria da Relatividade Geral de Einstein. Até Einstein achava. Mas, no final dos anos 60, cientistas estavam aptos a acreditar que tal coisa podia realmente existir. Meu livro conta a história fascinante de como isso aconteceu, como os cientistas começaram a acreditar nisso.

\section{Como você passou de Einstein e Picasso para buracos negros?}

Sempre me interessei pela controvérsia entre Chandra e Eddington. Todos sabem que os dois tiveram uma enorme discussão que arruinou suas vidas, mas ninguém lembra direito o que aconteceu, assim como ocorreu com a história de Copenhagen. Decidi então sentar e escrever.

\section{Como seus colegas cientistas vêem seu trabalho como escritor?}

Eles gostaram muito de alguém ter estabelecido uma conexão entre Einstein e Picasso. Alguns dos meus argumentos são conjeturais, mas a força da segunda evidência histórica - o efeito da avant garde sobre eles - é tão poderoso que certamente leva as pessoas a fazerem essa conexão. Cientistas de fato acreditam que há uma relação entre arte e ciência e estão interessados em ver isso ser discutido em nível cultural, porque estudos interdisciplinares estão se tornando muito importantes nos Estados Unidos e no Reino Unido, não sei ao certo no Brasil. As disciplinas básicas estão se quebrando. A física está se transformando em relatividade, astrofísica, cosmologia, física médica, física computacional e por aí vai. Todas essas áreas se alimentam umas das outras. Todos estão interessados na interdisciplinaridade e em discutir seus temas de um ponto de vista que possibilite que façam essa abertura.

Você está pensando em trabalhar em alguma outra relação entre física e arte? Como na relação entre mecânica quântica e surrealismo?

Certamente tenho outras idéias na cabeça, como por exemplo explorar mais a fundo as noções de intuição e estética, o que torna uma equação bonita, e o que realmente torna uma teoria bonita, o que uma pessoa pode dizer sobre a beleza como critério para a descoberta, para teorias futuras. 


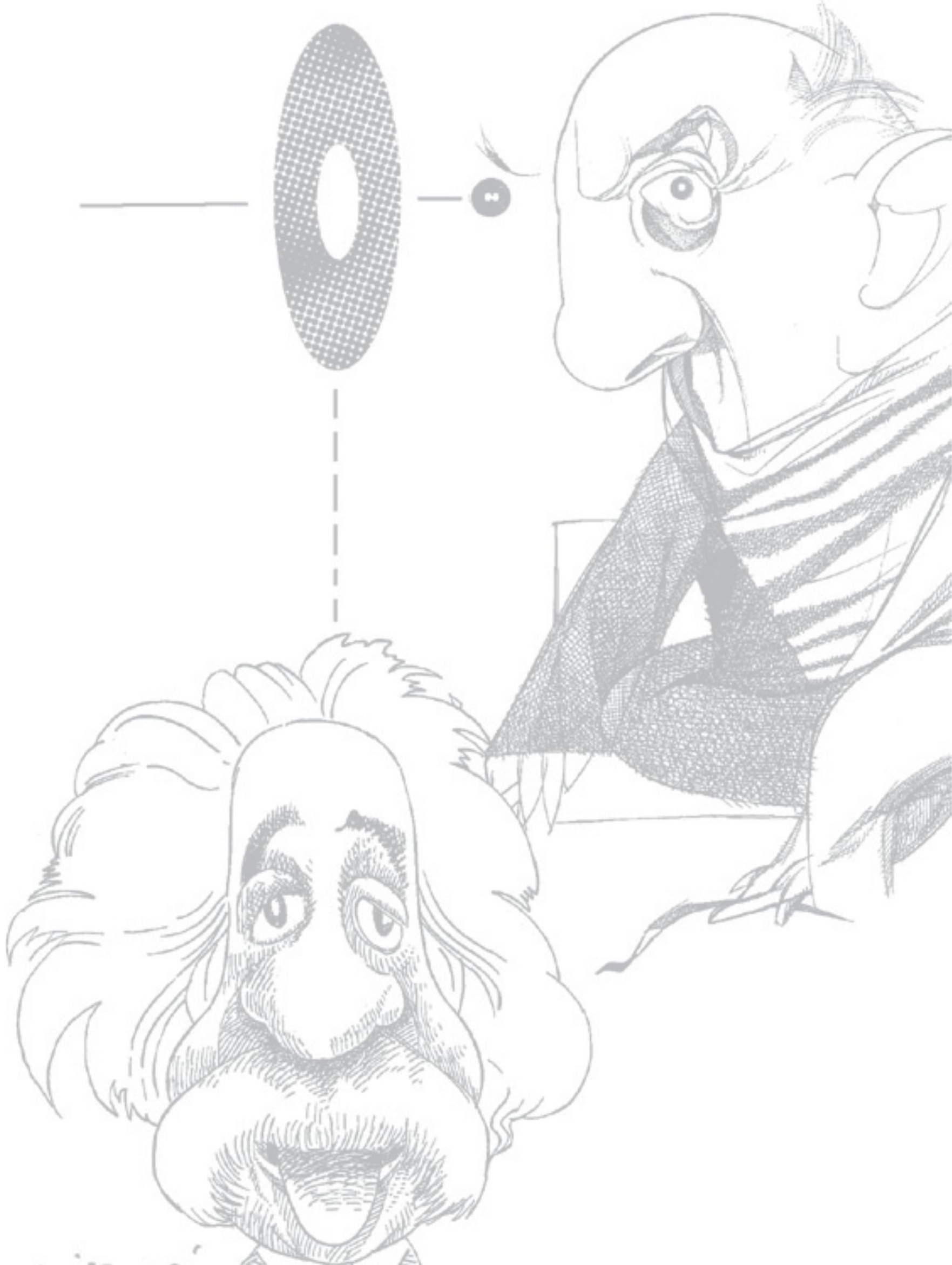

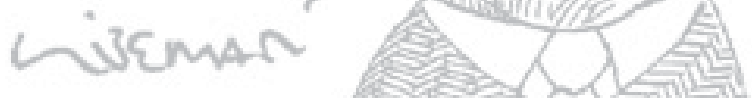

